\title{
Effect of early and delayed cord clamping on hemoglobin and hematocrit among full term neonates.
}

1. MBBS, FCPS (Paeds)

Senior Registrar Paeds Emergency Mayo Hospital Lahore.

2. MBBS, FCPS (Paeds)

Senior Registrar Pediatrics Medicsi Hospital.

3. MBBS, DCH, MRCPCH, FCPS Assistant Professor Pediatric Medicine

Services Institute of Medical Sciences (SIMS), Lahore.

4. MBBS, FCPS (Paeds) Senior Registrar Pediatric Medicine Mayo Hospital Lahore.

5. MBBS, FCPS

Assistant Professor Pediatric Medicine

Services Institute of Medical Sciences (SIMS), Lahore

6. MBBS, FCPS (Paediatric) Assistant Professor Paeds Emergency Medicine Mayo Hospital Lahore.

7. MBBS, PGPN (Boston, USA)

Medical Officer Pediatrics Government General Hospital Faisalabad.

Correspondence Address:

Dr. Muhammad Ahsan

Medical Officer Pediatrics

Government General Hospital,

Faisalabad.

ahsanjahangir194@gmail.com

Article received on:

$14 / 07 / 2020$

Accepted for publication:

$11 / 12 / 2020$

\section{INTRODUCTION}

Anemia is common disorder in pediatric population. In poor countries, iron deficiency leading to anemia is most prevalent in children < 5 years old. In Pakistan, overall $62.3 \%$ children are anemic out of which $4.1 \%$ are severely anemic. Iron deficiency anemia is associated with impaired physical growth and cognitive development in children less than five years of age.

A study in India showed that delayed cord clamping is safe, simple and low-cost procedure in reducing IDA in infants. Mean hemoglobin measured in early cord clamping group was
Saqib Aslam, Sadaf Minhas², Muhammad Azhar Farooq ${ }^{3}$, Beenish Bashir Mughal ${ }^{4}$, Farhan Zahoor ${ }^{5}$, Tehmina Maqbool ${ }^{6}$, Muhammad Ahsan ${ }^{7}$

STRACT... Objective: To compare the mean hemoglobin levels and frequency of Neonatology). Periods: December 2017 to June 2018. Material \& Methods: 190 full term eonates were selected and divided into 2 equal groups randomly: Early cord clamping $p$ after delivery and late cord clamping group. Two hours after clamping the venous blood $35(18.4 \%)$ neonates were anemic in this study. The polycythemia (HCT terms of gender, anemia, gestational age and birth weight ( $p$ values $0.663,0.852,0.700$ and respectively). The distribution of polycythemia was different among groups ( $\mathrm{p}$ value ( Mean Hb levels were statistically not different among some of the groups (gestational age $<40$ weeks, birth weight $<4 \mathrm{~kg}$ ) while HCT levels are significantly increased mean hemoglobin and hematocrit levels with increased frequency of polycythemia as compared to early cord clamping.

Key words: $\quad$ Hemoglobins, Infant, Newborn, Polycythemia, Prognosis, Umbilical Cord.

Article Citation: Aslam S, Minhas S, Farooq MA, Mughal BB, Zahoor F, Maqbool T, Ahsan M. Effect of early and delayed cord clamping on hemoglobin and hematocrit among full term neonates. Professional Med J 2021; 28(8):1114-1119. https://doi.org/10.29309/TPMJ/2021.28.08.5574 
However, a recent local study conducted in India showed that this delay in cord clamping showed in-significant effect on hemoglobin level and iron stores in the infants. ${ }^{4}$ In another recent study of Spain frequency of polycythemia was higher in full term newborns in which delayed cord clamping was done. Out of 80 patients exposed to early cord clamping 4 (5\%) developed polycythemia whereas out of 131 neonates exposed to delayed cord clamping 21 (16\%) developed polycythemia. ${ }^{5}$

The aim of this study was to compare the effect of early and delayed cord clamping on neonatal hemoglobin and hematocrit. As there is limited research regarding frequency of polycythemia. The results of this study would help to adapt a cord clamping technique that has an advantage of improved hematological profile and decreased risk of complications.

\section{MATERIAL \& METHODS}

This research was done in labor room and neonatology unit of KRL General Hospital Islamabad, six months (December 2017 to June 2018) after approval from the hospital ethical review committee ERC2016/02/01. Patients of both genders male and female including full term neonates, neonates having APGAR score of $8 / 10$ or above at one minute and mothers with $\mathrm{Hb} \geq 10 \mathrm{~g} / \mathrm{dl}$ at time of delivery were included the study. Patients including neonates born to mothers with pregnancy induced hypertension, gestational diabetes, poly or oligohydramnios, heart disease, anemia or preterm labor, neonates with any congenital or acquired illness were excluded from the study.

Early cord clamping was defined as umbilical cord clamping done within 15 seconds just after the delivery. While delayed cord clamping was defined as umbilical cord clamped at 60-180 seconds of birth or immediately after cessation of cord pulsations. Full term neonante was defined as neonate with gestational age of 37-41 weeks. Anemia was defined as central venous hemoglobin level $\leq 13.5 \mathrm{~g} / \mathrm{dl}$ measured at two hours of life. A neonate was labeled as having polycythemia when central venous hematocrit (HCT) was $>65 \%$ measured at two hours of life.

In this study, 190 mothers going to deliver were selected from Obstetrics labor room of KRL General Hospital, Islamabad after fulfilling the inclusion and exclusion criteria. Mothers were divided into two equal groups by table of random numbers. Hospital registration numbers and informed written consent was taken from all mothers. In group A after delivery the cord clamping was done early while in group $B$ the late cord clamping was done. The researcher was kept blind of the group identity. Hemoglobin and hematocrit were measured at two hours of life in the laboratory of KRL General Hospital, Islamabad that was verified by hematologist. All the data was entered on specially designed proforma.

Data was analyzed using SPSS version 17 for windows. Quantitative data like gestational age, birth weight, hemoglobin, hematocrit, and qualitative data like gender and frequency of polycythemia was analyzed. Mean and standard deviation were calculated for quantitative data. Frequency and percentages were calculated for analysis of qualitative data. Both groups were compared in terms of mean hemoglobin levels, hematocrit levels (independent sample t-test) and frequency of polycythemia (Chi square test). Effect Modifiers like gestational age, gender and birth weight were controlled by stratification. Post-stratification independent sample t test and Chi square test were applied. A p-value of $\leq 0.05$ was considered significant.

\section{RESULTS}

In this study, 190 neonates were enrolled after fulfilling inclusion and exclusion criteria. In group A, 44 out of $95(46.3 \%)$ patients were males and rest of 51 (53.6\%) were females; while in the group B, 47 of 95 (49.5) were male and rest 48 (51.5) were females. Frequency of anemia was $18.9 \%$ in group $A$ and $17.9 \%$ in group $B$. But the frequency of polycythemia in group $A$ was seen in 27 of 95 neonates $(28.4 \%)$ while it was seen in 45 of 95 cases in group B (47.4\%) ( $p=0.007)$, shown in Table-Il. Table-III. showing the mean + $\mathrm{SD}$ of all the quantitative variables seen in both the groups $(n=190)$. Both groups, $A$ and $B$ were 
compared among each other in terms of various quantitative variables. The results have been shown in Table-III. The results showed that both the $\mathrm{Hb}$ and hematocrit are significantly different among groups.

The data was stratified according to gestational age, neonatal gender and birth weight as shown in tables. The following table shows the comparison between groups for mean hemoglobin $(\mathrm{Hb})$ levels after stratification. The results showed that mean
$\mathrm{Hb}$ levels are statistically not different among some groups (gestational age $<40$ weeks, birth weight $<4 \mathrm{~kg}$ ).

The following table shows the comparison between groups for mean $\mathrm{HC}$ levels after stratification. The difference is not statistically significant among male group and category of birth weight $>4 \mathrm{~kg}$. The following table shows the comparison between groups for polycythemia prevalence after stratification.

\begin{tabular}{|c|c|c|c|c|c|c|}
\hline \multicolumn{2}{|c|}{ Parameter } & \multicolumn{3}{c|}{ Group } & Total & P-Value \\
\hline \multirow{2}{*}{ Anaemia } & & Yes & $18(18.9 \%)$ & $17(17.9 \%)$ & $35(18.4 \%)$ & \multirow{2}{*}{0.852} \\
\cline { 3 - 7 } & & No & 77 & 78 & 155 & 190 \\
\end{tabular}

Table-l. Showing comparing the frequency of anemia in both groups $(n=190)$.

\begin{tabular}{|l|l|l|c|c|c|c|}
\hline \multicolumn{2}{|c|}{ Parameter } & \multicolumn{2}{c|}{ Group } & Total & P-Value \\
\hline \multirow{2}{*}{ Polycythaemia } & & Yes & $27(28.4 \%)$ & $45(47.4 \%)$ & 72 & \multirow{2}{*}{0.007} \\
\cline { 2 - 7 } & & No & 68 & 50 & 118 & 190 \\
\end{tabular}

Table-II. Showing the frequency of Polycythemia among both groups $(n=190)$.

Parameter

Gestational age (wks)

Birth weight $(\mathrm{kg})$

Hemoglobin $(\mathrm{g} / \mathrm{dl})$

Hematocrit (\%)
Group

A
B

\begin{tabular}{|c|c|}
\hline $39.32 \pm 1.52$ & 0.700 \\
\hline $3.61 \pm 0.71$ & 0.491 \\
\hline $16.62 \pm 2.53$ & 0.001 \\
\hline $64.43 \pm 5.62$ & 0.002 \\
\hline
\end{tabular}

Table-III. Showing mean + SD of all the quantitative variables among groups $(n=190)$.

\begin{tabular}{|l|c|c|c|c|}
\hline \multicolumn{2}{|c}{ Parameter } & \multicolumn{2}{c|}{ Group } & P-Value \\
\hline \multirow{2}{*}{ Gestational age } & $<40$ weeks & $15.58 \pm 1.83$ & $16.16 \pm 2.46$ & 0.131 \\
\hline \multirow{2}{*}{ Gender } & $>40$ weeks & $15.34 \pm 2.08$ & $17.57 \pm 2.43$ & $<0.0001$ \\
\hline \multirow{2}{*}{ Birth weight } & Male & $15.85 \pm 1.86$ & $16.90 \pm 2.53$ & 0.027 \\
\cline { 2 - 5 } & Female & $15.23 \pm 1.90$ & $16.34 \pm 2.52$ & 0.015 \\
\hline & $<4 \mathrm{~kg}$ & $15.84 \pm 1.74$ & $16.50 \pm 2.48$ & 0.097 \\
\hline
\end{tabular}

Table-V. Hemoglobin level comparison after stratification of gestational age, gender, birth weight.

\begin{tabular}{|l|c|c|c|c|}
\hline \multicolumn{2}{|c}{ Parameter } & \multicolumn{2}{c|}{ Group } & P-Value \\
\hline \multirow{2}{*}{ Gestational age } & $<40$ weeks & $61.97 \pm 4.96$ & $64.11 \pm 5.17$ & 0.017 \\
\hline \multirow{2}{*}{ Gender } & $>40$ weeks & $62.41 \pm 4.25$ & $65.10 \pm 6.48$ & 0.071 \\
\hline \multirow{2}{*}{ Birth weight } & Male & $62.95 \pm 4.93$ & $62.87 \pm 5.59$ & 0.941 \\
\cline { 2 - 5 } & Female & $61.35 \pm 4.50$ & $65.96 \pm 2.26$ & $<0.0001$ \\
\hline
\end{tabular}

Table-VI. Hematocrit comparison after stratification of gestational age, gender, birth weight. 


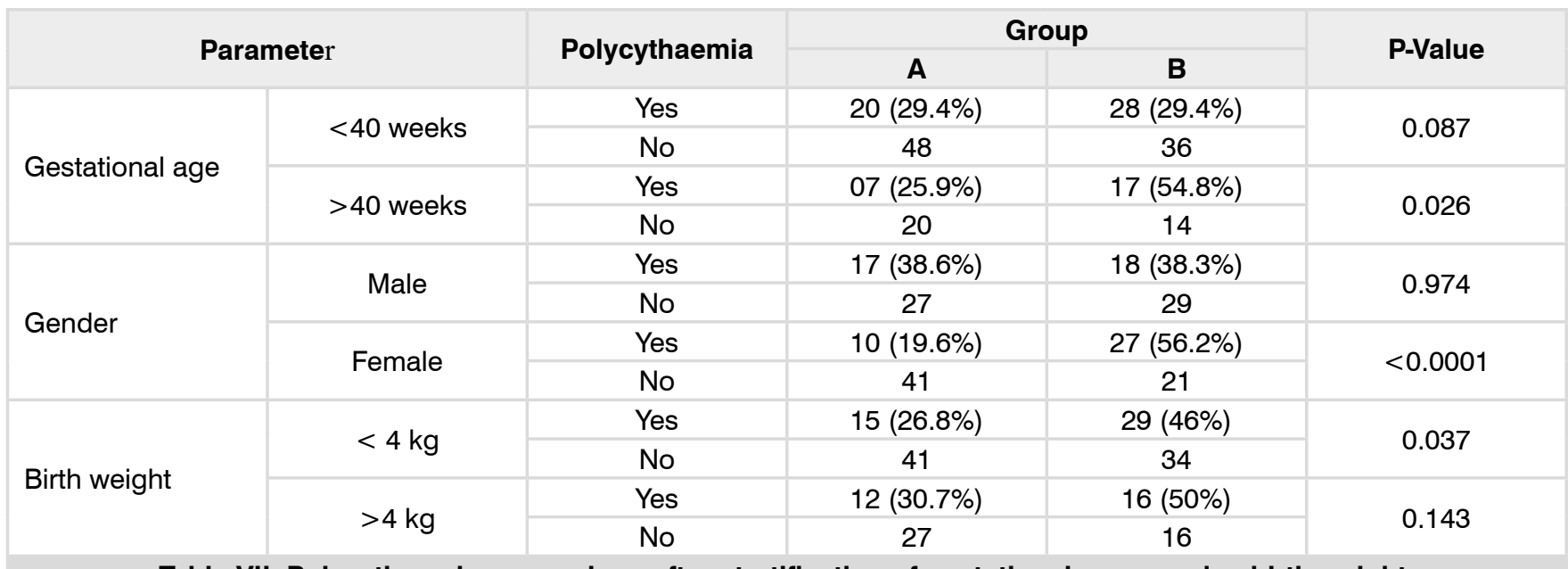

Table-VII. Polycythaemia comparison after stratification of gestational age, gender, birth weight.

\section{DISCUSSION}

The clamping of the umbilical cord in fundamental step during the third stage of labor. The discussion over the timing of clamping of the cord has been controversial. Initial attempts to quest for this are in the literature since start of the nineteenth century but insufficient results are available. The residual blood in the placenta is the focus in this issue. Long before around 2 decades back a study related to this topic was done and metaanalysis was done using its data with some other studies, it was concluded that after 40 seconds net-flow between placenta and infant reverses. And cord-clamping if delayed further 40 seconds can end up into a rise in the RPBV (residual placental blood volume) back to the level found when the cord was clamped before 20 seconds. ${ }^{6}$

Later on when the timing of cold clamping was studied on larger scale with more variables in focus then it came to recognition that cord clamping timing in normal deliveries may have no significant effect but late clamping in premature neonates is beneficial because it reduces the incidence of respiratory distress syndrome. ${ }^{7}$ In 2005 a literature review showed almost similar observations i.e. late cord clamping for full term neonates has no extra advantage. ${ }^{8}$ The late cord clamping increases the blood viscosity by $40 \%$ initially which may revert to near normal after 24 hours. ${ }^{9}$

Van Rheenen $\mathrm{P}$ and Brabin BJ, et al concluded that delayed cord-clamping in infants, with anemic mothers can decrease the risk of anemia in infants till 2-3 months age, without an associated rise in the chances of perinatal complications. This step just after the birth of a neonate in countries where fetal anemia is a common condition can improve the morbidity and mortality of neonates and infants. ${ }^{10}$

In 2008, Jahazi, A., et al. ${ }^{11}$ showed that there is no difference between the early and late clamping groups in terms of HCT levels (61 \pm 4.9 versus $61.6 \pm 4.5 \%$ for early and later groups respectively, $p$ value $>0.05$ ). This is contrary to the results of our study which showed that HCT in early and late clamping group is $62.09 \pm 4.75$ and $64.43 \pm 5.62 \%$ respectively with $p$ value of 0.002 . These conflicting results may have arisen due to two major differences. First the sample size of our study was 190 in total while above mentioned study had sample size of 64 only. Second difference was the timing of clamping. For our study, the early clamping was done at 15 seconds while in this study the early clamping was done at 30 seconds. In the same year another study had similar results as compared to my study. This study showed that late cord clamping coincides with an increased placental transfusion, expressed by higher hematocrit and emoglobin values, and larger left ventricle diameter at the end of the diastole, with no changes in peripheral perfusion or oxygen metabolism. ${ }^{12}$ Improvement in $\mathrm{Hb}, \mathrm{HCT}$ with increased risk of polycythemia after delayed cord clamping in neonates was shown by Rincon D, et al and Salari Z, et al. with 
no effect on the APGAR score and duration of third stage of labor. ${ }^{5,13}$

Even the chances of maternal postpartum hemorrhaging and/or neonate jaundice are also no affected, as was seen by Chien, PC, et al. in a study in 2015. ${ }^{14}$ Similar conclusions were made in a study in 2017. In our study, we limited to only single time hematological measurements in the immediate postnatal time, but the late cord clamping may have the beneficial effects later also.

One study by Andersson, O., et al. (2011) showed the delayed cord clamping, compared with early lamping, resulted in improved iron status and reduced prevalence of iron deficiency at 4 months of age, and reduced prevalence of neonatal anemia, without demonstrable adverse effects. ${ }^{3}$ Another recent study showed that serum ferritin levels are raised in late cord clamping group even at the end of six months of life. ${ }^{15}$ Somewhat conflicting results were shown by Agarwal, S., et al. (2016). ${ }^{4}$ It showed that at the end of one year there was no difference between groups in terms of iron stores, hemoglobin levels or growth parameters. These conflicting results may be due to the selection of participants as in $2017, \mathrm{Kc}, \mathrm{A}$., et al. showed that delayed cord clamping reduces anemia at 8 and 12 months of age in a high-risk population, which may have major positive effects on infants' health and development. ${ }^{16}$ So for low risk infants the early or late clamping might have no impact. Even after 6 months, mean $\mathrm{Hb}, \mathrm{HCT}$, serum iron levels were higher in delayed cord clamping group with no evidence of polycythemia or jaundice. ${ }^{15}$

Studies have shown that delayed clamping and cord milking should be done routinely in all deliveries. ${ }^{17-20}$ In our study, we stratified the data to counteract the effect of confounders. The stratification results showed the results showed that mean $\mathrm{Hb}$ levels are statistically not different among some of the groups (gestational age $<40$ weeks, birth weight $<4 \mathrm{~kg}$ ) while HCT levels are significantly different among male group and category of birth weight $>4 \mathrm{~kg}$.

\section{CONCLUSION}

The delayed cord clamping in neonates results in increased mean hemoglobin and hematocrit levels with increased frequency of polycythemia as compared to early cord clamping. The results should be ascertained on large scale to establish as protocol for late clamping of cord.

\section{Copyright $@ 11$ Dec, 2020.}

\section{REFERENCES}

1. Habib MA, Black K, Soofi SB, Hussain I, Bhatti Z, Bhutta ZA, et al. Prevalence and predictors of iron deficiency anemia in children under five years of age in Pakistan, A secondary analysis of national nutrition survey Data 2011-2012. PLoS One. 2016; 11(5):e0155051.

2. Dash MB, Murali R, Rajarajeswari S. Effect of delayed cord clamping on hemoglobin level among newborns in Rajiv Gandhi Government Women \& amp; Children Hospital, Puducherry. Am J Nurs Res. 2014; 2(1):7-11.

3. Andersson O, Westas L, Andersson D, Domellof $M$. Effect of delayed versus early umbilical cord clamping on neonatal outcomes and iron status at 4 months: A randomized controlled trial. BMJ. 2011; 343:d7157.

4. Agarwal S, Jaiswal V, Singh D, Jaiswal P, Garg A, Upadhyay $A$, et al. Randomised control trial showed that delayed cord clamping and milking resulted in no significant differences in iron stores and physical growth parameters at one year of age. Acta Paediatr. 2016; 105(11):e526-e30.

5. Rincon D, Foguet A, Rojas M, Segarra E, Sacristan E, Teixidor $\mathrm{R}$, et al. Time of cord clamping and neonatal complications, a prospective study. An Pediatr (Barc). 2014; $81(3): 142-8$.

6. Ogata ES, Kitterman JA, Kleinberg F, Dong L, Willis M, Mates $\mathrm{J}$, et al. The effect of time of cord clamping and maternal blood pressure on placental transfusion with cesarean section. Am J Obstet Gynecol. 1977; 128(2):197-200.

7. Ranjit T, Nesargi S, Rao PS, Sahoo JP, Ashok C, Chandrakala BS, Bhat $S$. Effect of early versus delayed cord clamping on hematological status of preterm infants at 6 wk of age. The Indian Journal of Pediatrics. 2015; 82(1):29-34.

8. Villabona B, Ayllon E, Thompson ML, Chiesa JM. Early or late umbilical cord clamping? A systematic review of the literature. An Pediatr (Barc). 2005; 63(1):14-21. 
9. Linderkamp O, Nelle M, Kraus M, Zilow EP. The effect of early and late cord-clamping on blood viscosity and other hemorheological parameters in full-term neonates. Acta Paediatr. 1992; 81(10):745-50.

10. Rheenen $P$, Brabin BJ. Late umbilical cord-clamping as an intervention for reducing iron deficiency anaemia in term infants in developing and industrialized countries: A systematic review. Ann Trop Paediatr. 2004; 24(1):3-16.

11. Jahazi A, Kordi M, Mirbehbahani NB, Mazloom SR. The effect of early and late umbilical cord clamping on neonatal hematocrit. J Perinatol. 2008; 28(8):523-5.

12. Zaramella P, Freato F, Quaresima V, Secchieri S, Milan A, Grisafi D, et al. Early versus late cord clamping: Effects on peripheral blood flow and cardiac function in term infants. Early Hum Dev. 2008; 84(3):195-200.

13. Salari Z, Rezapour M, Khalili N. Late umbilical cord clamping, neonatal hematocrit and Apgar scores: $A$ randomized controlled trial. J Neonatal Perinatal Med. 2014; 7(4):287-91.

14. Chien PC, Yang CC, Gau ML, Liu CY, Lee TY. The impact of late umbilical cord clamping on neonatal jaundice and postpartum hemorrhage: A Randomized Controlled Trail. Hu Li Za Zhi. 2015; 62(4):41-53.

15. Nesheli HM, Esmailzadeh S, Haghshenas M, Bijani A, Moghaddams TG. Effect of late vs early clamping of the umbilical cord (on haemoglobin level) in fullterm neonates. J Pak Med Assoc. 2014; 64(11):1303-5.
16. Kc A, Rana N, Malqvist M, Ranneberg L, Subedi K, Andersson $\mathrm{O}$,et al. Effects of delayed umbilical cord clamping vs early clamping on anemia in infants at 8 and 12 months: A randomized clinical trial. JAMA Pediatr. 2017; $171(3): 264-70$.

17. Alzaree F, Elbohoty A, Abdellatif $M$. Early versus delayed umbilical cord clamping on physiologic anemia of the term newborn infant. Open Access Maced J Med Sci. 2018; 6(8):1399-1404.

18. Vatansever B, Demirel G, Eren E, Erel O, Neselioglu $\mathrm{S}$, Karavar $\mathrm{HN}$, et al. Is early cord clamping, delayed cord clamping or cord milking best? J Matern Fetal Neonatal Med. 2017:1-4.

19. Jaiswal P, Upadhyay A, Gothwal S, Chaudhary $H$, Tandon A. Comparison of umbilical cord milking and delayed cord clamping on cerebral blood flow in term neonates. The Indian Journal of Pediatrics. 2015; 82(10):890-5.

20. Forghani F, Moghaddam MN. Evaluating the impact of delayed cord clamping and umbilical cord milking on the level of haemoglobin, bilirubin and ferritin 48 hours after delivery in term neonates during caesarean section. Ann Med Health Sci Res. 2018; 8:233-235.

\begin{tabular}{|c|l|l|l|}
\hline \multicolumn{3}{|c|}{ AUTHORSHIP AND CONTRIBUTION DECLARATION } \\
\hline Sr. \# & \multicolumn{1}{|c|}{ Author(s) Full Name } & \multicolumn{1}{|c|}{ Contribution to the paper } & Author(s) Signature \\
\hline 1 & Saqib Aslam & $\begin{array}{l}\text { Data Collection, Paper } \\
\text { writing. } \\
\text { Paper writing \& Data entry. }\end{array}$ \\
\hline 2 & Sadaf Minhas & $\begin{array}{l}\text { Discussion writing, Data } \\
\text { Analysis. } \\
\text { Data Analysis \& Review. }\end{array}$ \\
\hline 4 & M. Azhar Farooq & $\begin{array}{l}\text { Beenish Bashir Mughal } \\
\text { Review of Literature. }\end{array}$ \\
\hline 6 & Farhan Zahoor & Tehmina Maqbool & $\begin{array}{l}\text { Data Analysis, Review of } \\
\text { Literature. } \\
\text { Data Entry, Data Analysis, }\end{array}$ \\
\hline 7 & Muhammad Ahsan & $\begin{array}{l}\text { Paper writing. } \\
\text { Pane }\end{array}$ \\
\hline
\end{tabular}

